Malikussaleh Journal of Mathematics Learning (MJML)

p-ISSN: 2620-6315 | e-ISSN: 2620-6323

Homepage: https://ojs.unimal.ac.id/mjml/index

\title{
Social representations, human capital and knowledge production in the Covid-19 era
}

\author{
Cruz García-Lirios \\ ${ }^{1}$ Department of Complex Science, Universitas Huehuetoca, Mexico, 15417 \\ *Corresponding author: cgarciali@uaemex.mx
}

\section{ARTICLE INFO \\ Received: 23-07-2021 \\ Received in revised: 20-08-2021 \\ Accepted: 18-09-2021 \\ Available online: 30-10-2021}

\section{KEYWORDS}

Covid-19;

Human capital;

Knowledge production;

Social representations;

\begin{abstract}
A B S T R A C T
Studies of propaganda, security, warn youth and old age; 1 ) the systematic dissemination of crimes Attributed to political corruption; 2) state advertising as legitimate security administrator His rectory; 3 ) the de-legitimation of Citizens to Consider them incapable of preventative crime Initiatives; 4) are excluded by the industries older Assuming That They are incapable of selfmonitoring and self-care. Specify a model for studying the effects of advertising social security in the representations of aging, youth and old age. A non-experimental, retrospective and exploratory study with a nonrandom was Conducted selection of indexed sources the discretion of explanatory variables Between correlations paths... The model included three hypotheses to Explain the paths of correlations Between four and seven indicators constructs for each. The revised theoretical, conceptual and empirical frameworks warn the inclusion of other variables such as helplessness, self-control farsightedness, beliefs, attitudes and intentions That would complement the specified model. A comprehensive model would Explain the correlations paths from theoretical frameworks That Establish the Difference between crime prevention capabilities, systematic observation of corruption with emphasis on Impunity.
\end{abstract}

\section{INTRODUCTION}

Until July 2021, the pandemic has cut off the existence of four million, but sub-records allusive to atypical cases are recognized (Aguilar, 2019). In this scenario, the mitigation and containment policies, focused on the distancing and confinement of people, suggest the transition from the traditional classroom to the electronic blackboard, transforming teaching and learning (Aldana et al., 2018). In this sense, the formation of human capital in its academic, professional and labor dimensions could be more binding if it is considered that the contents can be recorded and disseminated in different technologies, devices, platforms and electronic networks.

Propaganda, considered a security system that implements the state to legitimize his rectory in terms of crime prevention and the administration of justice, has been studied social sciences in general and psychology in particular (Bolivar, 2019). Therefore, propaganda has been disseminated in various media including television, radio, press and cinema had skewed the content and set the topics for discussion at a public agenda.

However, with the emergence of the Internet and social networks, state propaganda took on a new face to not only spread images and speeches, but now expressions of anger, fear, anger, surprise or anxiety that intensified helplessness and farsightedness of risk events and threats citizenship (Bustos et al., 2018). Thus, digital networks no longer build an agenda focused on issues but on terms that Internet users adopt to express their discontent or pleasure at any news, message, event or celebrity.

However, traditional propaganda, unlike modern propaganda, generates reflections against and for the guidance of the State (Carreon, 2019). This is because impacts differentially young audiences with respect to the largest public (Carreon, 2020). While older adults used the radio and the press to have a close view of your local situation and the television and film to build a represen- 
tation of the world in any case legitimated the rectory of the state and a nearby authority to represent him, young Netizens use networks to establish two types of threats focused on identity theft and ridicule. Both aspects, the legitimation of state violence by the perception of insecurity and the feeling of helplessness, as well as the representation of the privacy and identity depend on digital networks, reveal state propaganda as omnipresent actor in society.

The theory of social representations is introduced by Serge Moscovici in 1961, from his doctoral thesis called Psychoanalysis his image and his public work addresses the social representation of psychoanalysis and the image of the psychoanalyst in modern French society to analyze the areas where social representations were configured (Carreon et al., 2017). Moscovici takes as a basis the theoretical contributions of Durkheim collective representations which relate to the forms of thought that dominate a society, consisting of myths, religion, science, the dominant beliefs in a given society, which are incorporated in each one of its individuals.

This theory is recognized as a valuable contribution in the fields of social psychology, education, among others; now it constitutes an important reference for other social sciences for the study of social phenomena so the theory of social representations has been the theoretical foundation in conducting various investigations from various fields. Social representations are guides to action, determine behavior, social practices and dynamics of social relations (Piña, 2009). Cover retained information, selected and interpreted judgments made about the object and its environment, stereotypes and beliefs.

The representation functions as a system of interpretation of reality that governs the relations of individuals between their physical and social environment, and to determine their behavior or practices. It is a guide for action, guides the actions and social relations (Abric, 2001). It is a system of pre-decoding of reality since it determines a set of anticipations and expectations (Abric, 2001: 13). For Moscovici representation it is always a representation of someone speaks and shows, communicates and expresses. After all it produces and determines behavior, because at the same time defines the nature of the stimuli around us and provoke us, and the meaning of the answers that we give them (Carreon et al., 2018). The social representation is a particular form of knowledge, whose function is the development of behaviors and communication among individuals (Moscovici, 1961: 17). The theory of social representations responds to four functions:

1. Functions know. They allow us to understand and explain reality. 2 . Functions identity. Define the identity and allow safeguarding the specificity of the groups. 3 . Functions Orientation: drive behaviors and practices and 4 .
Justificadoras functions. Can justify a posteriori the postures and behaviors (Abric, 2001).

A social representation is composed of two elements. 1. The objectification regard to the development and operation 2. The anchoring of social representation. They can be analyzed in three dimensions: 1 . The information relates to the organization of the knowledge possessed by a group regarding a social object. 2 . The field of representation or image, refers to the idea of image, social model, the specific and limited content of the proposals which relate to a specific aspect of the object of representation and 3 . The attitude has to do with favorable or unfavorable in relation to the object of social representation (Piña, 2009) global orientation.

However, the "effect" on "the members of each society have a social reality that apparently share appears mediated by a complex network of links and meanings from which the" social "is emerging with a symbolic dimension that paralyzes any attempt mechanist to attribute a generic to a dialectical process of double construction "objectivity (Elizarrraz, 2020). Subjectivity is understood as a socio psychological construction that stands as the product of a permanent interpretation of the individual, the group and the social and projects in specific social contexts and ways of acting, thinking and feeling from which they are organized and they made tangible individualities that accompany tour of the human within its largest and most complex construction: society.

If propaganda highlights the importance of identity and privacy while younger you are with respect to perceptions of insecurity of the elderly, then aging, youth and old age are transient categories set based on trust towards the contacts of the digital networks or in the case of the elderly, from their ability to represent their capabilities and resources, security, skills and knowledge (Fuentes-Avila, 1995). Dementia is a syndrome characterized by a progressive deterioration of cognitive functions accompanied by psychiatric symptoms and behavioral disturbances resulting in progressive disability the patient.

In Mexico there are programs designed by major public institutions such as the National Institute of Geriatrics, Care National Institute on Aging, Department of Health, etc., to serve the elderly, but from a very small picture, without offering an integrative approach, regardless of the patient, diagnosed with dementia, such as a human being who deserves respect and inclusion (MJ Robles, 2011). There is currently no curative treatment for people with dementia and care focuses on promoting wellness and improve the quality of life (Lucas-Carrasco, 2007). Older adults are a vulnerable group to present a series of physical, biological and psychological characteristics that put them at greater disadvantage (Garcia, 2017). The care of these children lies with the (mostly women) and to a lesser extent siblings, or by institutions, if the economic level allowed; and may be - 
the case that they are abandoned.

In the Federal District, institutions have focused only provide seniors "certain" benefits that allow them to meet their basic needs, however, no specific public policies for the care of those diagnosed with $\mathrm{AD}$, offering them a Quality service (Garcia, 2018). Also, there are no models for care that allows them to improve their quality of life. Magdalena Contreras demarcation is one of the 16 delegations in the Federal District is divided. As governing bodies of the capital of the Republic they are decentralized delegations of the Federal District. It is located south west of Mexico City.

From this context it is necessary to carry out the study of social representations of the elderly in general and care of Alzheimer's in particular, since the media generate information that those involved in aging and care dementias assimilated as part of their cultural repertoire, which will define their strategies for treatment and prevention of mental illness (Garcia, 2019). Thus, the culture of respect for the elderly will determine family care as an inherent process to their family and groups of friends, but a culture that ponders youth over old age represents an abuse.

Social representations are instances of processing information around which time is considered as a cultural process, but such is the influence of the group of belonging to the care of the elderly will be determined by the SCPs such as: "But know the devil that old devil "," as you see I saw, as I see I see "," If you want to grow old, then the tontejo haste " (Garcia, 2020). Therefore, the study of social representations from Alzheimer generated a comprehensive picture of the image of the caregiver against the attitudes of the elderly regarding the SCPs. The diagnosis of social representations of Alzheimer care possible to anticipate scenarios of conflict between the elderly and the caregiver. In this sense, it will be feasible toexplain the changes that are generated in the interplay between actors and propose models for intervention to reduce the effect of SCPs in the attitudes of the elderly and social representations of Alzheimer care.

The model included three assumptions that explain the correlations between four constructs inferred by seven indicators set each as structural modeling criteria (Garcia et al., 2016). The social representations of the guidance of the State security affect collective representations of solidarity and cooperation of the largest identities (Garcia et al., 2017). The trajectory anticipated scenarios legitimization of violence of institutions committed to crime prevention and combating crime, even if the administration of justice is not guaranteed (Garcia et al., 2018). The logical route explains the process in which older adults assimilate their dependence on the state and local authorities in order to establish law and order. Such trail warns that differences between youth identities and older identities involves two types of governance than in the case of older identities is only possible through the use of violence against those who violate the laws and in the case of youth identities They employ the ideological apparatuses such as the media.

Social Security representations affect digital representations of youth identities privacy. It is a path that explains the influence of traditional media in digital networks, as disseminate information concerning the harassment (stalker, buller, troler) which would affect confidence towards the contacts on Facebook, Twitter, Instagram, WhatsApp Messenger or the main networks of interrelation among young identities. Although collective representations and digital representations are differentiated instruments of legitimation of State may be conjoined with the purpose of influencing any identity is juvenile or greater (Hernandez et al., 2018). This is the case of policies of common resources-information on environmental threats and risks, financial or social, that not only affect one sector or another, but could also affect future generations.

The objective of the present work was to establish a systematic review and meta-analysis model for the literature corresponding to social representations in the formation of human capital, considering a period from December 2019 to July 2021. What are the homogeneous random effects of the literature concerning social representations of human capital formation in the Covid-19 era?

The premises that explain the homogeneous random effects of the formation of human capital on the academic, professional and labor spheres, considering the pandemic as the determining scenario of the virtual classroom, suggest that there are significant differences between teaching and learning with respect to the traditional classroom (Amemiya, 2020). This is so because academic, professional and labor training are standardized in the virtual classroom and diversified outside of it (Bermudez, 2019). In other words, training in the traditional classroom is oriented towards the reproduction of knowledge, while professional and labor training is distinguished by forming intangible assets that generate value for knowledgeproducing organizations.

\section{METHOD}

The study was carried out with 100 abstracts of articles included in journals indexed to international repositories, applying the Helsinki protocol for the preparation of systematic reviews and meta-analysis of homogeneous random effects (see Table 1). The Delphi technique was used for the qualification of the abstracts, considering a value of 1 to the findings that refer to the social representations of the academic training, 2 for the human capital and 3 for the knowledge production. 
Table 1. Descriptive sample

\begin{tabular}{|c|c|c|c|c|c|c|c|c|c|}
\hline & \multicolumn{3}{|c|}{ Social representations } & \multicolumn{3}{|c|}{ Human Capital } & \multicolumn{3}{|c|}{ Knowledge Production } \\
\hline & 2019 & 2020 & 2021 & 2019 & 2020 & 2021 & 2019 & 2020 & 2019 \\
\hline Academia & 4 & 3 & 3 & 3 & 3 & 2 & 3 & 2 & 2 \\
\hline Conacyt & 3 & 2 & 5 & 1 & 2 & 3 & 2 & 3 & 3 \\
\hline Copernicus & 5 & 4 & 4 & 2 & 4 & 2 & 2 & 1 & 1 \\
\hline Dialnet & 3 & 1 & 3 & 4 & 3 & 4 & 4 & 4 & 4 \\
\hline Dimensions & 2 & 3 & 2 & 5 & 2 & 3 & 3 & 3 & 3 \\
\hline Ebsco & 4 & 2 & 4 & 3 & 1 & 5 & 1 & 2 & 5 \\
\hline Frontiers & 2 & 4 & 2 & 4 & 2 & 5 & 3 & 3 & 2 \\
\hline Google & 1 & 4 & 2 & 2 & 5 & 3 & 3 & 3 & 1 \\
\hline Latindex & 1 & 2 & 1 & 2 & 3 & 4 & 2 & 4 & 3 \\
\hline Mendeley & 2 & 1 & 3 & 2 & 1 & 1 & 1 & 4 & 2 \\
\hline Microsoft & 3 & 5 & 3 & 3 & 3 & 2 & 4 & 4 & 3 \\
\hline Redalyc & 4 & 3 & 4 & 3 & 4 & 1 & 1 & 5 & 4 \\
\hline Scielo & 5 & 3 & 4 & 1 & 4 & 1 & 5 & 1 & 2 \\
\hline Scopus & 3 & 2 & 3 & 4 & 3 & 4 & 4 & 4 & 1 \\
\hline Zenodo & 2 & 4 & 1 & 3 & 5 & 3 & 2 & 2 & 3 \\
\hline Zotero & 4 & 3 & 2 & 5 & 2 & 2 & 3 & 3 & 4 \\
\hline
\end{tabular}

Note: Elaborated with data study.

The Delphi inventory was used, using the judges' ratings, as well as the review and meta-analysis protocol based on the prevalence of the categories with respect to the evaluated findings (Hernandez, 2019). The data were processed in the JASP package to establish homogeneous random effects parameters.

\section{RESULTS AND DISCUSSION}

The normal distribution values suggest the analysis of the relationships between the categories of information search and the revised, qualified and coded findings of the reviewed literature (see Table 2).

Table 2. Descriptive instrument

\begin{tabular}{|c|c|c|c|c|c|c|c|c|c|}
\hline \multirow[t]{2}{*}{$\mathrm{A}$} & \multicolumn{3}{|c|}{ C1 } & \multicolumn{3}{|c|}{ C2 } & \multicolumn{3}{|c|}{ C3 } \\
\hline & $\mathrm{M}$ & SD & $\mathrm{K}$ & M & SD & $\mathrm{K}$ & $\mathrm{M}$ & SD & $\mathrm{K}$ \\
\hline a1 & 2.8 & .39 & 1.2 & 2.4 & .72 & 1.8 & 2.3 & .54 & 1.4 \\
\hline a2 & 2.3 & .43 & 1.1 & 2.9 & .83 & 1.0 & 2.7 & .43 & 1.9 \\
\hline a3 & 2.4 & .20 & 1.1 & 2.3 & .62 & 1.7 & 2.0 & .35 & 1.7 \\
\hline $\mathrm{a} 4$ & 2.3 & .44 & 1.1 & 2.0 & .41 & 1.6 & 2.8 & .46 & 1.4 \\
\hline a5 & 2.8 & .24 & 1.4 & 2.1 & .30 & 1.5 & 2.9 & .41 & 1.3 \\
\hline $\mathrm{a} 6$ & 2.9 & .38 & 1.1 & 2.7 & .53 & 1.0 & 2.6 & .23 & 1.7 \\
\hline a7 & 2.3 & .56 & 1.1 & 2.8 & .24 & 1.9 & 2.5 & .24 & 1.0 \\
\hline a8 & 2.0 & .43 & 1.3 & 2.3 & .31 & 1.8 & 2.1 & .36 & 1.1 \\
\hline a9 & 2.1 & .36 & 1.5 & 2.5 & .54 & 1.1 & 2.6 & .59 & 1.3 \\
\hline a10 & 2.4 & .20 & 1.8 & 2.4 & .39 & 1.5 & 2.3 & .65 & 1.2 \\
\hline a11 & 2.5 & .37 & 1.9 & 2.0 & .43 & 1.4 & 2.5 & .83 & 1.4 \\
\hline $\mathrm{a} 12$ & 2.8 & .41 & 1.1 & 2.1 & .56 & 1.2 & 2.0 & .42 & 1.7 \\
\hline a13 & 2.2 & .46 & 1.2 & 2.8 & .76 & 1.5 & 2.2 & .44 & 1.6 \\
\hline a14 & 2.4 & .59 & 1.3 & 2.9 & .32 & 1.9 & 2.7 & .51 & 1.9 \\
\hline a15 & 2.9 & .67 & 1.1 & 2.7 & .32 & 1.7 & 2.9 & .65 & 1.8 \\
\hline a16 & 2.3 & .43 & 1.4 & 2.6 & .43 & 1.2 & 2.6 & .74 & 1.4 \\
\hline a17 & 2.0 & .23 & 1.5 & 2.0 & .54 & 1.4 & 2.5 & .35 & 1.6 \\
\hline $\mathrm{a} 18$ & 2.9 & .43 & 1.6 & 2.3 & .13 & 1.0 & 2.0 & .42 & 1.0 \\
\hline a19 & 2.8 & .39 & 1.3 & 2.2 & .47 & 1.3 & 2.1 & .53 & 1.3 \\
\hline $\mathrm{a} 20$ & 2.3 & .30 & 1.4 & 2.1 & .40 & 1.6 & 2.2 & .36 & 1.4 \\
\hline $\mathrm{a} 21$ & 2.2 & .37 & 1.3 & 2.3 & .29 & 1.8 & 2.5 & .32 & 1.1 \\
\hline $\mathrm{a} 22$ & 2.1 & .42 & 1.4 & 2.6 & .20 & 1.9 & 2.3 & .43 & 1.6 \\
\hline $\mathrm{a} 23$ & 2.0 & .44 & 1.4 & 2.5 & .18 & 1.6 & 2.6 & .44 & 1.8 \\
\hline $\mathrm{a} 24$ & 2.4 & .47 & 1.2 & 2.9 & .19 & 1.9 & 2.5 & .61 & 1.9 \\
\hline
\end{tabular}

Note: Elaborated with data study. A = Abstract, M = Mean, SD = Standard Deviation, $\mathrm{K}=$ Kurtosis, $\mathrm{C} 1$ = Social Representations, C2 = Human Capital, $\mathrm{C} 3$ = Knowledge Production.

In order to be able to observe the configuration of the categories, the correlation and covariance matrix was estimated. The parameters show possible routes of relationships between these categories with respect to the findings reviewed, considering a structure of three categories and 24 indicators, eight of which were related to each category (see Table 3). 
Table 3. Correlations and covariations

\begin{tabular}{|c|c|c|c|c|c|c|c|c|c|}
\hline & $\mathrm{M}$ & SD & $\mathrm{K}$ & C1 & $\mathrm{C} 2$ & $\mathrm{C} 3$ & C1 & $\mathrm{C} 2$ & $\mathrm{C} 3$ \\
\hline $\mathrm{C} 1$ & 24.35 & 18.54 & 1.43 & 1.000 & & & 1.987 & .548 & .632 \\
\hline $\mathrm{C} 2$ & 26.57 & 10.54 & 1.89 & $.543^{* *}$ & 1.000 & & & 1.970 & .437 \\
\hline C3 & 20.54 & 14.35 & 1.07 & $.654^{*}$ & $.436^{* * *}$ & 1.000 & & & 1.986 \\
\hline
\end{tabular}

Note: Elaborated with data study. A = Abstract, $\mathrm{M}=$ Mean, SD = Standard Deviation, $\mathrm{K}=$ Kurtosis, C1 = Social Representations, C2 = Human Capital, C3 = Knowledge Production. ${ }^{*} \mathrm{p}<.01{ }^{* *} \mathrm{p}<.001 ;{ }^{* * *} \mathrm{p}<.0001$

In order to observe the structure of axes, trajectories and relationships, we proceeded to estimate the model of structural equations (see Figure 1). The results show the prevalence of these three category axes, as well as their relationship with the abstracts selected in the repositories consulted.

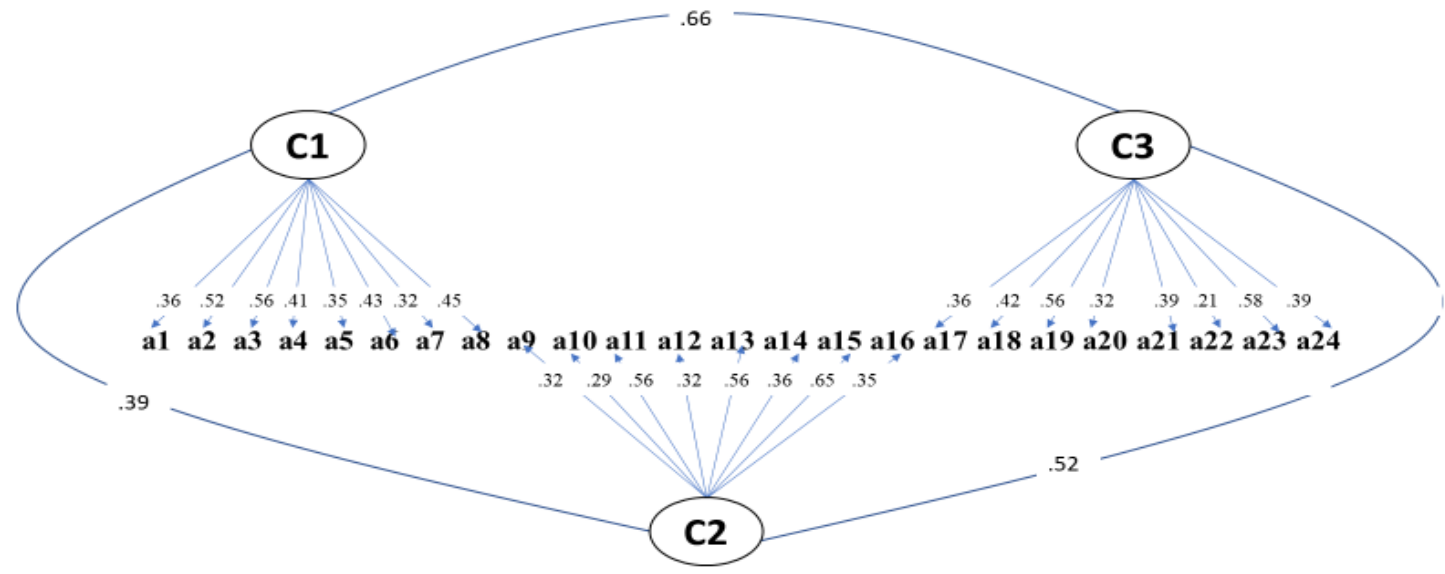

Figure 1. Structural equation modelling

Note: Elaborated with data study. $\mathrm{A}=$ Abstract, $\mathrm{M}=$ Mean, $\mathrm{SD}=$ Standard Deviation, $\mathrm{K}=$ Kurtosis, $\mathrm{C} 1=$ Social Representations, $\mathrm{C} 2=\mathrm{Human}$ Capital, $\mathrm{C} 3=$ Knowledge Production, $\mathrm{e}=$ Error measurement abstract, $\mathrm{d}=$ Disturbance measurement category.

The adjustment and residual parameters $(\chi 2=23.28$ (16 df) $\mathrm{p}>$.05; GFI = .997; CFI .990; RMR $=.007$ ) suggest the non-rejection of the homogeneous random effects hypothesis, although a more exhaustive review could corroborate this assumption. That is, the literature corresponding to the categories of representations, human capital and production of knowledge is reflected in 24 findings that the judges linked to each category in three rounds. This is so because it is an emerging area of study of Covid-19 and its impact on the virtual classroom.

The contribution of this work to the state of knowledge lies in the specification of a model for the study of the incidence of social representations in collective representations, digital representations and youth identity or the identity of the elderly with regard to safety and privacy spread in the media.

However, from other theoretical and conceptual frameworks-autocontrol, agenda setting, elaboration likelihood, reasoned action, planners explanatory behavior trajectories dependency relationships between variables indefensión, farsightedness, beliefs, attitudes are noted, intentions that could complement the specification of this work (Garcia and Carreon, 2013). Some specified models have shown that the messages of the traditional media have more influence on audiences older than youth identities (García, 2012). This is because security policies are focused on the emotions of the audience and manage to penetrate their emotions more easily through television, as images and speeches are instruments of greater influence than the data in sectors with low educational and older (Garcia et al., 2013), although increasingly persuasion strategies are focused on the messages on local corruption administered by a federal entity (Garcia et al., 2015), generating a socio political identity and no difference age groups, but processing capabilities (Garcia et al., 2014).

However, the study Mejia, Carreon and Garcia (2016) showed that older adults feel more guilt than youth with respect to insecurity, and they attribute to their age committing crimes against them. This means that the state propaganda directed to hold the non-citizen crime prevention, it affects mostly older adults who feel unable to confront the violence of civil courts (Hernandez, 2020). Therefore, a comprehensive model not only incorporate theoretical, conceptual and empirical frameworks, but also the perspective of young and older adults who watch propaganda differentially security, plus their perspective capacity generates an identity crime prevention but they may not always achieve that goal given the surrounding information regarding security at different levels and modalities. 


\section{CONCLUSION}

Social representations, human capital and the production of knowledge are a trident that the literature and the judges surveyed place as part of a joint response of HEIs to Covid19 and its effects in the virtual classroom, considering distancing and social confinement. In relation to public policies, strategies and biosafety programs, the objective of this work was to establish the homogeneous random effects of three categories with respect to the findings reported in the literature. That is to say, the anticipation of a risk scenario, accidents, infections, diseases and deaths can be observed in the relationships between the categories and the indicators.

\section{Acknowledgements}

The authors would like to thank all parties who have assisted in the research and writing of this manuscript so that it deserves to be widely published to the academic community.

\section{REFERENCES}

Abric J. (1994). Social representations and practices. Mexico: Philosophy and Contemporary Culture.

Aguilar-Fuentes, J. A., García-Lirios, C., Bermúdez-Ruiz, G., PérezOrtega, M. I., Bolivar-Mojica, E., de Nava Tapia, S. L., ... \& Pérez-Crisanto, G. (2019). Especificación de un modelo para el estudio de la percepción de utilidad. Revista de Comunicación y Salud, 9(2), 47-54. DOI:

http://doi.org/10.35669/revistadecomunicacionysalud.2019.9(2) $.47-54$

Aldana-Balderas, W. I., Rosas-Ferrusca, F. J., \& Lirios, C. G. (2018). Especificación de un modelo para el estudio de la agenda de la seguridad pública. Atlante Cuadernos de Educación y Desarrollo, (septiembre). DOI:

http://ri.uaemex.mx/handle/20.500.11799/98789

Amemiya, M. (2020). Retrospective metanalysis of the random and homogeneous effect of the validity of the risk perception scale. American Journal of Applied Scientific Research, 10 (4), 25-35

Bermudez, G. (2019). Meta- analytic validity of the social entrepreneurship inventory: a random effects size study. Global Journal of Management \& Business Research, 19 (10), 10-19

Bolívar, E. (2019). Specification of a business migration flow study model. Cinzontle, 10 (1), 4-16

Bustos, J. M. Ganga, F. A. Llamas, B. \& Juarez, M. (2018). Contrastación de un modelo de decisión prospectiva e implicaciones para una gobernanza universitaria de la sustentabilidad. Margen, 89 (1), 1-16

Carreon, J. (2019). Fixed effects model of fuzzy variables in the formation of intellectual capital. International Journal of Engineering Research and Development, 15 (9), 1-7

Carreon, J. (2020). Neural networks of scenarios, phases and discourses of violence of the Internet. Journal of Neurology \& NeUro Toxicology, 4 (3), 1-9
Carreon, J. and García, C. (2013). Theories of public safety and crime perception. Margen, $71: 1-16$

Carreon, J. Blanes, A. V. \& Garcia, C. (2018). Confiabilidad y validez de un modelo de gobernanza percibida de la inseguridad. Sin Frontera, 11 (27), 1-53

Carreon, J. Hernandez, J. \& Garcia C. (2017). Una revisión teórica para el estudio de la gobernanza de la seguridad pública. Epsys, 4 (1), 1-15

Elizarraraz, G. (2020). Meta- analytical validity of the scale of perception of technological utility. International Review of Psychiatry, 3 (8), 1-7

Fuentes, M. (1995). Subjectivity and social reality: A socio psychological approach Journal of Psychology, 1, 107-120..

Garcia, C. (2012). The structure of the perception of public insecurity. Liberabit, 18 (1), 37-44

Garcia, C. (2018). Reliability and validity of an instrument that measures knowledge management in a public university in central Mexico. Tlatemoani, 27, 285-304

Garcia, C. (2019). Exploratory factor structure of the security public. International Systems Journal, 23 (1), 82-86

Garcia, C. (2020). Specification of a model for the study of entrepreneurship. Advances in research Journal of Discoveries Multidisciplinary, 49 (1), 01.04

Garcia, C. Carreon, J. \& Hernandez, J, (2017). Gobernanza de la seguridad pública. Revisión de la literatura para una discusión del estado del conocimiento de la identidad sociopolítica delictiva. Margen, 84 (1), 1-17

Garcia, C. Carreon, J. Hernandez, J. and Mendez, A. (2013). Systems sociopolitical violence. Polis, $36: 1-17$

Garcia, C. Carreon, J. Hernandez, J. Mejia, S., Garcia, and E. Rosas, F. (2014). Criminal social and political identity in Mexico. Hispano - American Notebooks Psychology, 14 (1) $5-16$

Garcia, C. Carreon, J. Hernandez, J., Aguilar, J., Rosas, F. Morales, M. and Garcia, E. (2015). Reliability and validity of an instrument that measures perceptions of corruption.American Thought, 8) 15), 108-120

Garcia, C., Carreon, J. \& Hernandez, J. (2016). Gobernanza del terror a la delincuencia. Eureka, 13 (2), 168-185

Garcia, C., Martinez, E. and Rivera, PE (2018). Labor flexibility in higher education. Inclusions, 5, 51-69

Hernandez, J. (2019). Internet harassment in the documentary and expert agenda. Asian Journal of Science \& Technology, $10(8), 1-3$

Hernández, J. (2020). Specification of a model of social intervention model against Covid-19. Biomedical Journal of Scientific and Technical Research, 26 (3), 62-65

Hernandez, TJ, Sanchez, A., Espinosa, F., Sanchez, R. and Garcia, C. (2018). Model of entrepreneurship and innovation lucidity in micro coffee companies in central Mexico. Eureka, 15 (1), 96-107

Lucas, R. (2007). Quality of life and dementia Medicine Clinic., 1, 349-354. 
Mejia, S. Carreon, J., Garcia, C. (2016). Psychological effects d ela violence and insecurity in older adults. Eureka, 13 (1), 3955

Moscovici, S. (1979). Psychoanalysis, its image and its public. Argentina: Huemul SA
Rivera, B. Garcia, C. Garcia, E., Rosas, F., Lemon, G. Carreon, J. Hernandez, J. and Morales, M. (2015). . Contrast a model of political distrust Psiencia, 7, 1 DOI August 1 to $1: 10.5872$ / psiencia / 7.1.21

Robles, M. (2011). Diagnostic information in dementia. Spanish Journal of Geriatrics and Gerontology, 1, 163-169. 